\title{
Family Support and Its Effects on Avoiding the Complexity of Schizophrenia "A Field Study on a Wide Sample of Schizophrenia"
}

\author{
Laid Fekih \\ Department of Psychology, University of Tlemcen, Tlemcen, Algeria \\ Email address: \\ fekih_laid@yahoo.fr \\ To cite this article: \\ Laid Fekih. Family Support and Its Effects on Avoiding the Complexity of Schizophrenia "A Field Study on a Wide Sample of \\ Schizophrenia”. International Journal of Education, Culture and Society. Vol. 3, No. 3, 2018, pp. 61-67. \\ doi: $10.11648 /$ j.ijecs.20180303.14
}

Received: June 10, 2018; Accepted: July5, 2018; Published: October 29, 2018

\begin{abstract}
This research aims to assess, compare and identify the effect of family support on the improvement or complexity of psychopathological schizophrenia case through evaluation of symptoms especially that is a chronic disorder that needs longterm care and assistance. The method used in this research is purely clinical and descriptive following the collected data from the sample of 150 schizophrenic patients suffering from different psychopathological forms, were followed up during two years. The findings of this research were: Only $47 \%$ schizophrenic receive the true support from their family. There is a negative correlation $\left(\mathrm{r}_{\mathrm{pb}}=-0.75 \mathrm{p}<0.001\right)$ between "family support" and the "complexity of disease". There was statistical significant difference (0.01) between schizophrenia cases that receives support and those who do not receive it in terms of behavioral and cognitive symptoms in favor of schizophrenia receiving family support. No effect was observed between them in term of the conviction of delusional beliefs.
\end{abstract}

Keywords: Family Support, Improvement, Complexity, Schizophrenia

\section{Introduction}

Schizophrenia affects around $0.3-0.7 \%$ of people at some point in their life [1]. It affects about 2 million people in the United States at a cost of $\$ 70$ billion per annum [2]. In 2000, the world health organization found the prevalence and incidence of schizophrenia to be roughly similar around the world, with age-standardized prevalence per 100,000 ranging from 343 in Africa to 544 in Japan and Oceania for men and from 378 in Africa to 527 in Southeastern Europe for women [3]. Currently, there are no curative treatments for schizophrenia [4].

Family psycho-education as a treatment for schizophrenia was developed 40 years ago almost simultaneously and independently by investigators who at the time were not family therapists [5]. The family formally perceived as the cause of the problems has become "a solution to keep the person in his environment". The way of thinking about the family in psychiatry has evolved considerably through three major currents [6]: The family makes one of its members sick. It is the group, as a whole, who is sick. The family is both the problem and the solution. The study of CookDarzens \& al [7] shows that the strongest evidence base of "Multiple Family Therapy (MFT's) is for schizophrenia and chronic psychoses, making its psycho-educational model one of the best available practices for these disorders". (Domingues-Martinez \& al) [8] Confirms that Family-toFamily (FTF) as Education Program is clearly effective, it confirms the importance to provide routine family psychoeducation as an additional element in providing health care services to severe mental illness. Community also intervenes to reduce negative emotional attitudes and improve understanding of disorder, regardless of gender or age. In other study [9] through regression analyses it's found significant increases in positive appraisal but no significant decreases in negative appraisals for those in the FTF condition. In the context of overall benefits from taking FTF, these relationships reflect the FTF curriculum's emphasis on 
positive coping (e.g., strength and empowerment) and the potential value of strategies that help caregivers increase positive appraisal.

Family members of those with schizophrenia are more likely to live a critique situation, imbalance and perhaps psychic or somatic troubles, the suffering is greater and cost is higher. Although the patient is in a state of unconsciousness and inability to interact normally, physically and sensibly, it is best for him to live among his family members. The proper awareness and sound knowledge of schizophrenia contribute in one way or another to mitigating the impact of the disease on the family [10].

When reviewing the literature published between 1966 and 1993, on the efficacy and effectiveness of psycho-educational family interventions in the treatment of schizophrenia patients, there is substantial evidence that these interventions, when added to pharmacotherapy, reduce the rate of patient relapse, and suggestive evidence that they improve patient functioning and family well-being. Interventions with multifamily groups that include the patient may be of superior benefit for subgroups of patients [11].

While schizophrenic patients are far from reality and are often unable to perform normal functions, suffering from the pathological symptoms that accompany their illness leads to fatigue the patient permanently. The life of schizophrenia is chaotic, unable to concentrate or achieve his works; he finds many difficult to establish social relations due to many illusions, hallucinations and delusions. Here, schizophrenia is discussed in its general form without going into details of each type of schizophrenia.

A ten-year work conducted with the entourage of schizophrenic patients at the National Union of Friends and Families of Psychiatric Patients has led to a knowledge of what the siblings of patients are experiencing more precisely [12]. This survey of 600 siblings of schizophrenic patients made it possible to highlight the repercussions of the disorders:

- 54\% of siblings believe that the illness of their loved one has repercussions on their health, this figure reaches $61 \%$ for the group of siblings from ten to 21 years;

- $45 \%$ feel a sense of danger, and this feeling lasts throughout life with an average of $43 \%$ regardless of the age of the siblings who responded to the survey (from 10 years to 79 years).

The symptoms associated with schizophrenia don't only affect the patient, but also family members and the surrounding community, which leads to the aversion of the surrounding by the lack of understanding of symptoms [13]. When the disease develops and the family discovers its reality, the journey of hope and disappointment begins with the discovery of the unknown, then the search of cure, often the family stumbles in the right direction to receive treatment, believing that they offer their patient the best that they can in his eternal recovery. For that Goldstein [14] confirms "If a patient is in regular contact with family members, it is reasonable to engage these relatives in the patient's care".
In addition, beyond the increased burden on families, introducing care without home consent puts pressure on all members of the family group: the patient but also those close to him who have to be coerced. The effects of the introduction of coercion in the family sphere on relational exchanges and the climate of the home are not discussed [15]. As it has often been described with regard to tutors or curators, the most helper and protector, may become for the patient the one who hinders, abuses a power which does not seem to him legitimate [16].

In the study of Pharoah et al [17], they usually focus on attempting to improve the interpersonal environment by providing the following key elements:

- Assessment and problem formulation (as with cognitive behavioral therapy)

- Information about the nature of the illness, its prognosis, and treatment

- Intervention and problem solving strategies to address areas of conflict and concern, and goal setting to improve social and interpersonal functioning of all family members.

This forgetfulness of oneself in front of the suffering of the other is often mentioned in all the literature which deals with the question of family life one of whose members is seriously ill or handicapped [18].

Research, particularly in North America, on families in psychiatry shows this shift in care to families, have identified conditions to strengthen the collaboration of families but not to question the principle of this collaboration. They focused on two main themes: the assessment of caregiver burden (Family Burden) [19], and the level of emotionality in the (Expressed Emotion) family [20]. Many psycho-educational training programs stem from these research movements confirming that the family has a role to play in the care of the patient. In fact, the family today is seen more as a resource than as abstacle to healing.

The question is not to decide which the fairest vision is but to show that the passage from one ideology to another must absolutely be accompanied by a clinical and theoretical reflection on the impact of this ideology on the everyday and the well-being of families and the sick. Family interventions can involve close family members and carers and staff groups for people living in inpatient environments [21].

The general treatment of the patient is one of the most important factors to stabilize his condition, social integration and prevent relapses. It is therefore necessary to avoid stigmatizing him or treating him with cruelty, indignity or anger [22]. Excessive care and overeating must also be avoided, they have the same effect. Over taking care and paying attention the room arrangement and cleaning, especially with regard to the evacuation of all that can be used to harm the self or others.

A familial grief reaction in schizophrenia is complicated by the ambivalence of recognizing chronic illness in a loved one while having recurring demands for action to cope with an evolving situation [7]. If the patient enters the hospital, contact with him and his commitment to the visit or telephone call must be established, in order to avoid the idea 
that he is neglected or rejected by his family. The patient should also not be reminded of his strange or pathological behavior, and to talk him about his "basic needs and matters of public life".

Research has shown that a family with a schizophrenic patient does suffer from stressors and depression [23]. The emergence of a chronic disease triggers a centripetal family process of social adaptation to the disease. Symptoms, loss of function, need for transformation or acquisition of new roles associated with the disease, and fears of loss through death, require a refocusing of the family on itself, it identifies this movement whatever the disease, but this observation is very specific when it comes to schizophrenia while the person who suffers the disorder lives a similar experience [24].

Family members should avoid differences among themselves about how to deal with the patient, and what steps to take with him. It is necessary to contact and coordinate with the treating physician and to form an integrated team [18] (Wynne, 1994). There is no single method for dealing with schizophrenic patients, for each case has its own style, although there are common commonalities in treatment and treatment [25]. In some cases, the patient abandons cooperation with his family, and may refuse to take his medicine, it is necessary to contact the treating physician, and search with him for possible solutions. It may convince the patient in a certain way, or change the form of treatment from tablets, for example to drops of drink or long-acting injection.

Psychiatrists Bantman and Parage [26] refer to three criteria at the origin of the new status of the family:

- Essential partner: the evolution of care practices.

- The contingent difficulties of the economic context in public psychiatry.

- Closure of hospital beds without opening alternative structures.

Interventions are often delivered with single families, although those delivered to groups of families simultaneously have also been shown to be effective [27]. Group family intervention may be more effective than standard care at reducing family burden. Moderate to low quality evidence suggests mutual support groups for caregivers may improve families' and patients' knowledge about mental illness and coping strategies, and reduce stress and burden [5]. Recently, training has taken an important role in the various mental health services. to equip staff with the skills to work collaboratively with families and to understand and support their needs, especially information, education and reducing stress within the family environment. [28]

The patient's behaviors, however strange, harmful or violent, are not deliberate, nor consciously conceived, but are the result of a disturbance in his mind. It is therefore necessary to avoid reciprocity, persecution or ridicule. There is no point in trying to convince him that he is wrong. This is an opportunity to share both the family's observations, which offer a unique insight into the patient's environment and the clinician's specialized knowledge [22].

In other cases, the patient may be silent and refuse to participate in any activity or family meeting. In this case, it is useful to talk to him and work to attract him to social activities and the frequency of the attempt may be useful, but the most useful is to resort to appropriate medical treatments. One of the most common symptoms of schizophrenia is the patient's neglect of himself, his cleanliness and his hunch. In this case, it is necessary to avoid dealing with emotion, anger, shouting or strict orders in the absence of interest in the advice provided. The chronic or insidious progression of schizophrenia may lead to relatives minimizing the implications of their loss, leading to poor grief resolution [25]. Compared with usual psychiatric care, family intervention was more effective in reducing care burden over all follow-up periods. Family intervention was also superior to usual care with regards to caregiving experience in the short term and improved utilization of formal support and family functioning over longer-term follow up. Mutual support is more effective than psycho-education in improving family functioning when measured 1 to 2 years after the intervention but had equivalent effects on utilization of formal support services. [29]

\section{The Problematic}

The family is the first institution in which individuals develop, learn the basic skills that help them to move and achieve their social interaction. The role of the family becomes more important and sensitive in the event that one of its members faces special difficulties or chronic disease as schizophrenia. Basing on this, what is the reality of family support in people with schizophrenia in Algerian society? Is it possible to overcome those symptoms that affect the life of the patient, his family and its surroundings?

This research will attempt to answer the following questions:

- What is the psychological and emotional impact of schizophrenia on family members? And what is the reality of family support?

- Is there a correlation between family support and the complexity of disease?

- Is there a difference between schizophrenia cases that receives support and those who do not receive it in terms of behavioral and cognitive symptoms?

- Is there a difference between schizophrenia cases that receives support and those who do not receive it in terms of the conviction of delusional beliefs?

\section{The Aim of the Study}

This research aims firstly to know the rate of the support that the family members provided by caring for individuals with schizophrenia, and secondly to assess, compare and identify the effect of family support on the improvement or complexity of psychopathological case through evaluation of symptoms.

The purpose of this study is to provide concrete, actionoriented information based on the scientific data to help schizophrenic and family having a member with schizophrenia to improve their wellbeing 


\section{Method}

\subsection{Sample}

To achieve the purpose of this research was chosen intended sample selected from hospitals containing 150 schizophrenic suffers from different psychopathological forms, In addition to their families, were followed up for two years in the west of -Algeria-, sampled on the random basis. A research assistant gave questionnaires to their families and told them that they were not to state their names to ensure anonymity. Approximately 20 minutes was required to complete the questionnaire.

\subsection{Search Tools}

Data collection tools were a Family Support Questionnaire for Mental Illness (FSQMI) designed by the researcher, it is a questionnaire containing 18 questions, the purpose of the survey is to gather information about kind of family support, their feelings while taking care. Brief Psychiatric Rating Scale (B-PRS), and a Brief Cognitive Assessment Tool for Schizophrenia (B-CATS).

It should be noted that (BPRS) and (B-CATS) questionnaires are a reliable tools translated in Arabic and approved by specialists in clinical psychology and psychiatry, the validity measurement of this scales was conducted by Fekih and Benosman [30] using both methods of reliability and validity tests by re-testing, with $r=85$. The results for the validity test were stable, that indicate the quality and usefulness of the tests.

\subsection{Statistical Methods Used in the Study}

The study on the current descriptive approach, to analyze data from the study, the researcher used a range of statistical methods as the Percentages, Biserial Correlation $\left(\mathrm{r}_{\mathrm{pb}}\right)$, and Independent-Samples T test.

\section{Results}

Table 1. Shows the percentages of kinds of family support.

\begin{tabular}{|c|c|c|}
\hline \multirow{2}{*}{ Kinds of family support } & \multicolumn{2}{|c|}{ Families $\mathbf{N}=150$} \\
\hline & $\mathbf{F}$ & $\%$ \\
\hline -Schizophrenia is quickly detected by the family & 72 & 48 \\
\hline -Regular contact with the inpatients. & 70 & 47 \\
\hline -Adherence to the drug treatment system, and the periodic review of the doctor & 69 & 46 \\
\hline -Patient adaptation with the drug & 70 & 47 \\
\hline -Family contribution to the development of treatment plan with mental health worker & 67 & 45 \\
\hline -The patient continues to perform his normal life tasks & 67 & 45 \\
\hline -Develop skills that help the schizophrenic social integration & 72 & 48 \\
\hline
\end{tabular}

Table 1 indicates that only 47\% schizophrenic receive the true support from their family, while more than 53\% of families are either completely neglected, or finds many difficulties to take care of her patient suffering from schizophrenia.

Table 2. Shows the percentages of psychological and emotional impact of schizophrenia on family members.

\begin{tabular}{|c|c|c|}
\hline \multirow{2}{*}{ Psychological and emotional problems } & \multicolumn{2}{|c|}{ Families $\mathbf{N}=150$} \\
\hline & $\mathbf{F}$ & $\%$ \\
\hline -Denial of illness by the family. & 57 & 38 \\
\hline -Feeling angry and failing & 90 & 60 \\
\hline -Feeling tired, frustrated and chaos for a long time. & 88 & 59 \\
\hline -Feeling hopeless and unable to follow. & 112 & 75 \\
\hline -The feeling of constant tension due to fear of the unknown. & 100 & 67 \\
\hline -Fear of being unable to progress sin treatment. & 105 & 70 \\
\hline -Stress due to the abnormal behaviour of the patient. & 82 & 55 \\
\hline -The frustration of many attempts to treat and absence of healing. & 114 & 76 \\
\hline -Misunderstanding of family situation and lack of help from others. & 88 & 59 \\
\hline
\end{tabular}

Table 2 shows that the psychological and emotional impact of schizophrenia on family members is significant. Where the majority by $75 \%$ to $76 \%$ of the families are Feeling frustrated due to absence of healing, feeling hopeless and unable to follow. Also note that more than half of the families suffer from denial, angry, failing, tiredness, frustration, stress, grief and worry.

Table 3. Shows the results of the correlation between family support and the complexity of disease (B-PRS) and (B-CATS).

\begin{tabular}{|c|c|c|c|c|c|c|}
\hline \multicolumn{7}{|c|}{ Brief Psychiatric Rating Scale (B-PRS) } \\
\hline $\mathrm{n} 1$ & n0 & $\overline{x_{11}}$ & $\bar{x}$ & $\mathrm{~S}$ & $\mathrm{rpb}$ & sign \\
\hline 70 & 80 & 32 & 49 & 3.6 & -0.75 & $\mathrm{p}<0,001 * *$ \\
\hline \multicolumn{7}{|c|}{ Brief Cognitive Assessment Tool for Schizophrenia (B-CATS). } \\
\hline $\mathrm{n} 1$ & n0 & $\bar{x}_{1}$ & $\bar{x}$ & S & $\mathrm{rpb}$ & sign \\
\hline 70 & 80 & 43.45 & 59.7 & 9.3 & -0.27 & $\mathrm{p}<0.024 *$ \\
\hline
\end{tabular}

**Correlation is significant at the 0.001 level (two tailed test). 
Table 3 shows that there is a negative correlation between "family support" and the "complexity of disease", that means whenever the patient receives assistance, support and understanding from their family whenever contribute to the healing of the patient or alleviate the severity of schizophrenic disorders.

Table 4. Shows the results of independent-samples T test, to study the difference between schizophrenia cases that receives support and those who do not receive it in terms of behavioral, cognitive symptoms, and the conviction of delusional beliefs.

\begin{tabular}{|c|c|c|c|c|c|c|c|}
\hline & \multicolumn{2}{|c|}{ receives support $n=70$} & \multicolumn{2}{|c|}{ who do not receive it $n=80$} & \multirow[b]{2}{*}{$\mathbf{t}$} & \multirow{2}{*}{ Df } & \multirow{2}{*}{ Sign } \\
\hline & $\overline{x_{1}}$ & S1 & $\overline{x_{2}}$ & S2 & & & \\
\hline Behavioral and cognitive symptoms & 22.23 & 3.4 & 15.7 & 4.3 & 10.36 & 148 & 0.00 \\
\hline Conviction of delusional beliefs. & 14.7 & 5.3 & 13.2 & 4.13 & 1.97 & 148 & 0.13 \\
\hline
\end{tabular}

Table 4 shows that there was statistical significant difference $(0.01)$ between schizophrenia cases that receives support and those who do not receive it in terms of behavioral and cognitive symptoms in favor of schizophrenia receiving family support. No effect was observed between them in term of the conviction of delusional beliefs.

\section{Discussion of Results}

The current study found that only $47 \%$ schizophrenic receive the true support from their family, while more than $53 \%$ of families are either completely neglected, or find many difficulties to take care of her patient suffering from schizophrenia.

The percentage of regular contact with the patient in Algerian society is small compared to the regular contact with the patient, estimated at 74 in American society; up to $75 \%$ of people with schizophrenia are in regular contact with their families [31]. This finding shows that family attention to schizophrenia is still incomplete and requires more family awareness of the importance of mental care, especially schizophrenia, Because of the desperation of the susceptibility of schizophrenia to healing. The family is required to overcome the feelings of despair, negativity and the difficulties encountered in the process of treatment, both in terms of attention, follow-up and interaction with the therapeutic team or in terms of providing the appropriate atmosphere that contribute to the alleviation of the disease.

The most effective treatment for schizophrenia patients is usually a combination of family support, medication, psychological counseling and self-help resources. It is crucial that a person living with schizophrenia receives the full support of their family, friends, and community services when onset appears for the first time.

All health care interventions when treating schizophrenic patients should be concerned with family education on both treatment and prevention before psychotic symptoms are exacerbated [32]. Subjective burden includes the psychological and emotional impact of mental illness on family members. A change in the opinion and attitudes of many mental health professionals in relation to family therapy is absolutely necessary [33]. According to Onwumere [34] it is wrong to consider the family interventions as a part of mental health worker's effective role as current evidence suggests that the existence of good practice and provision for family interventions.
The current study also finds that the psychological and emotional impact of schizophrenia on family members is significant. Where the majority by $75 \%$ to $76 \%$ of the families are Feeling frustrated due to absence of healing, feeling hopeless and unable to follow. Also note that more than half of the families suffer from denial, angry, failing, tiredness, frustration, stress, grief and worry. The study of Koujalgi and Patil [35] has shown that family members of patients with schizophrenia experienced considerable high degree of family burden compared to depressive disorder group. This has an important implication for management of patient with schizophrenia. The stresses of illness exacerbations coupled with limited social and coping capabilities contribute to subjective burden [36]. According to Falloon [37] in "one single-family modality, the solution is Behavioral Family Management, which includes assessment, problem analysis, education, and development of problemsolving skills and effective communication approaches. The mental and physical health of family members can be affected if an index patient has a chronic psychiatric disorder. Other study confirms that there was no significant difference between the study groups with respect to effect of burden on physical and mental health of others. In other words, the burden equally affects physical and mental health of caregivers of dementia and schizophrenia patients [38].

The family should be aware that the stress caused by the presence of the disease has a negative effect both on the patient and on her ability to support the patient. The importance of family involvement includes enhancing family strengths, and increasing patients family support networks [39]. The family has an opportunity to develop its ability to deal with stress, crises and create a stable emotional atmosphere that helps the patient to improve his situation. As is required of the family to invest in the time spent by the patient and be filled with various activities. Staying away from blaming the patient and letting him know that he is a burden on others, this does not help him but it aggravate the situation. Avoiding as far as possible behaviors or comments that alienate the patient, he must be accompanied at social events and be helped to integrate into society. On this basis (McFarlane) [40] points out that: "The most recent application in first episode and prodromal psychosis, combined with other evidence-based interventions, is yielding perhaps the most promising results yet achieved - substantial return of functioning and avoidance of psychosis altogether". 
The current study found that there is a negative correlation between family support and the complexity of disease, that means whenever the patient receives assistance, support and understanding from their family whenever contribute to the healing of the patient or alleviate the severity of schizophrenic disorders, while patients from disintegrated or hard-line families face difficult times, their condition quickly regress, which complicates the disease and increase suffering from recurrent schizophrenia. These results are consistent with the findings of Sawant and Jethwani, [41] when they confirm that the correlations of behavior control, affective responsiveness, and general functioning were highly significant. Thus providing support to the notion that despite the level of schizophrenia, if the social support perceived from the family is higher, it would help in the better functioning of the family. An integrated approach is only feasible if professionals work collaboratively and understand that schizophrenia is a mental health disorder that affects multiple areas of the patient and requires a comprehensive approach [33].

Similar findings were found by Torres-González [42] that there is a relationship between schizophrenia and medical illnesses as an independent variable, mental health and social services as a dependent variable. Also Koyama et al [32] founds a positive correlation between neurocognitive functioning and interpersonal problem solving skills in patients with schizophrenia. Cognitive deficits of psychotic patients could also lead to their negative perception about solutions of different family's problems.

The present study has shown that there was statistical significant difference $(0.01)$ between schizophrenia cases that received support and those who didn't receive it in terms of behavioral and cognitive symptoms in favor of schizophrenia receiving family support: that means the application of family support together with standard treatment is more effective in the improvement of the clinical state than when only standard treatment is applied. While it is clear that family intervention is more effective than routine care in preventing relapse [43]. This shows that it is important to assess family functioning as the perceptions of the family environment of a schizophrenic patient often predict his relapse.

- No effect was observed between them in term of the conviction of delusional beliefs. This is due to the nature of schizophrenia, and the difficulty of disappearance of the conviction of delusional beliefs, whether or not the victim received family support. Deficits in personal memory, judgment, or planning can lead to poor problem-solving and poor social skills in schizophrenia. The functional decline associated with the negative symptoms leads to social and economic difficulties and puts a burden on the family.

\section{Conclusion}

The current study concluded that the problems and issues related to having a family member with schizophrenia are many and very complex. The solution is difficult and raises another problem, which is as follows: Is it necessary to take care of the patient or his family or both of them.

Despite the efforts of the family to cure the schizophrenia, especially in terms of following medical treatment, which they consider as adequate treatment, but they are often surprised by the illness regression, in this stage, the family's search of the real treatment begins; subjective burden includes the psychological and emotional impact of mental illness on family members

The support of family is one of the fundamental variables in therapeutic integration through the combination of efforts of all. In the end, the family should be aware that schizophrenia is not the fault of anyone, and not a result of a lack of upbringing, but it is a mental illness due to many etiologies; the treatment is very slow and needs the support of all family members. There is no reason to move away from society, every family deserves help to reduce it tension and know how to deal with the patient, especially which the patients with schizophrenia are at risk of undetected somatic co morbidity, especially at late and more developed disease stages.

In particular, the community must accept the disease, the patient and recognize that there is a member of the family is ill and needs support and treatments. Understanding the disease, conditions that surrounding patient and symptoms, helps the family to found the resolutions.

\section{References}

[1] Van Os, J., \& Kapur, S. (2009). Schizophrenia. Lancet, $374,635-5$.

[2] Schultz SK, Andreasen NC. (1999). Schizophrenia. Lancet. 353: $1425-1430$.

[3] Ayuso, M., \& Jose, L. (2013). Global burden of schizopherenia in the year 2000 (pdf) World Wealth Organization.

[4] Van Os, J., Burns, T., Cavallaro, R., Leucht, S., Peuskens, J., Helldin, L., et al. (2006). Standardized remission criteria in schizophrenia. Acta Psychiatr Scand, 113 (2), 91-95.

[5] William, R., \& McFarlane. (2016). Family Interventions for Schizophrenia and the Psychoses: A Review. Family Process journal, 55(3), 460-482

[6] Ausloos, G. (1995). La compétence des familles: temps, chaos, processus. Ramonville, Saint-Agne, Erès.

[7] Cook-Darzens, S., Gelin, Z. \& Hnedrick, S. (2017). Evidence base for multiple family therapy (mft) in non-psychiatric conditions and problems: A review (part two). Journal of Family Therapy, DOI: 10.1111/1467-6427.12177.

[8] Domingues-Martinez, T., Rascon-Gasca, M.L. \& AlcantaraChabelas, H. (2017). Effects of family-to-family psychoeducation among relatives of patients with severe mental disorders in Mexico City. Psychiatric Services, 68(4), 415-418.

[9] Toohey, M. J., Muralidharan, A., Medoff, D., Lucksted, A. \& Dixon, L. (2016). Caregiver positive and negative appraisals: Effects of the national alliance on mental illness family-tofamily intervention. Journal of Nervous and Mental Disease, 204(2), 156-159. 
[10] Tessler, R. C., Killian, L. M., Gubman, G. D. (1987). Stages in family response to mental illness: an ideal type. Psychosoc Rehab J, 10: 4-16.

[11] Dixon, L. B., \& Lehman, A. F. (1995). Family interventions for schizophrenia. Schizophrenia Bulletin, 21(4), 631-643.

[12] Davtian, H. (2003). Les frères et sœurs de malades psychiques, résultats de l'enquête et réflexions. Paris, Unafam.

[13] Rafiyah, (2011). Review: burden on family caregivers caring for patients with schizophrenia and its related factors. Nurse Media J Nurs, 1 (1), 29-41.

[14] Goldstein, M. J. (1995). Psychoeducation and relapse prevention. Int Clin Psychopharmacol, 90 (5), 59-69.

[15] Scelles, R. (1998). Tutelles aux majeurs protégés et fratrie: la nécessité d'instaurer une réflexion sur la protection de la personne handicapée adulte, Handicaps et inadaptations, Les cahiers du CTNERHI.

[16] Phelan, M. D. Evelyn, J. Bromet. (1998). Psychiatric Illness and Family Stigma Schizophrenia Bulletin, Volume 24, Issue $1,115-126$

[17] Pharoah, F. M., Mari, J. J., Streiner, D. (2006). Family interventions in schizophrenia. Cochrane Database of Systematic Reviews, (4), CD000088.

[18] Scelles, R. (2010). Liens fraternels et handicap. In: La vie de l'enfant. Mercues, Erès.

[19] Thompson, E. H., \& Doll, W. (1982). The burden of families coping with the mentally ill: an invisible crisis. Fam Relat, 31, 379- 88 .

[20] Vaughn, C., \& Leff, J. (1976). The measurement of expressed emotion in the families of psychiatric patient. Br J Soc Clin Psychol, 2, 157-65.

[21] Oliver, N., \& Kuipers, E. (1996). Stress and its relationship to expressed emotion in community mental health workers. Int $\mathrm{J}$ Soc Psychiatry, 42(2), 150-159.

[22] Wynne, L. C. (1994). The rationale for consultation with the families of schizophrenic patients. Acta Psychiatr Scand, 90 (384), 125-32.

[23] Chan, S. W., Yip, B., Tso, S., Cheng, B. S., Tam, W. (2009). Evaluation of a psychoeducation program for Chinese clients with schizophrenia and their family caregivers. Patient Educ Couns, 75(1), 67-76.

[24] Rolland, J. S. (traduit par S. Cook, 2001). Maladie grave et handicap: comment la famille y fait face?. In: Walsh F, éd. Normal family processes. New York, Guilford Press, 444-73.

[25] Parkes, C. M. (1998). Facing loss. BMJ, 316, 1521-4.

[26] Bantman, P. Parage, N. (2001). La question de l'alliance thérapeutique avec la famille dans le traitement de la schizophrénie: réflexions et perspectives cliniques actuelles. Kortenberg, Ligue Belge de Schizophrénie.

[27] McFarlane, W. R., Lukens, E., Link, B., et al. (1995). Multiple-family groups and psychoeducation in the treatment of schizophrenia. Arch Gen Psychiatry, 52 (8), 679-87.

[28] Conneely, P. (2016). Working with Families. In: J. Clewes \& R. Kirkwood (Eds.) Diverse Roles for Occupational Therapists. Keswick: M \& K Publishing. pp. 195-210.

[29] Ma, C. F., Chien, W. T. \& Bressington, D. T. (2017). Family intervention for caregivers of people with recent-onset psychosis: A systematic review and meta-analysis. Early Intervention in Psychiatry, doi.org/10.1111/eip.12494.

[30] Fekih, L., \& Benosman, D. (2013). Translation and calibration of Brief Psychiatric Rating Scale to Arabic language. Psychometric Journal, 01, 77-110

[31] Lehman, A. F., \& Steinwachs, D. M. (1998). Translating research into practice: the Schizophrenia Patient Outcomes Research Team (PORT) treatment recommendations. Schizophr Bull, 24, 1-10

[32] Koyama, A., Akiyama, T., Miyake, Y., Kurita, H. (2004). Family functioning perceived by patients and their family members in three Diagnostic and Statistical Manual-IV diagnostic groups. Psychiatry Clin Neurosci, 58, 495-500.

[33] Caqueo-Urízar, A., Rus-Calafell, M., Urzúa, A., Escudero, J., \& Gutiérrez-Maldonado, J. (2015). The role of family therapy in the management of schizophrenia: challenges and solutions. Neuropsychiatric Disease and Treatment, 11, 145-151. http://doi.org/10.2147/NDT.S51331.

[34] Onwumere, J., Grice, S., \& Kuipers, E. (2016). Delivering Cognitive-Behavioural Family Interventions for Schizophrenia. AUSTRALIAN PSYCHOLOGIST, 51(1), 5261. DOI: $10.1111 /$ ap. 12179.

[35] Koujalgi, S. R., \& Patil, S. R. (2013). Family Burden in Patient with Schizophrenia and Depressive Disorder: A Comparative Study. Indian Journal of Psychological Medicine, 35(3), 251-255. http://doi.org/10.4103/02537176.119475

[36] Solomon, P., \& Draine, J. (1995). Subjective burden among family members of mentally ill adults: relation to stress, coping, and adaptation. Am J Orthopsychiatry, 65, 419-427.

[37] Falloon, I. R. H. (2002). Cognitive-behavioral family and educational interventions for schizophrenic disorders. In: Hofmann SG, Tompson MG. Treating Chronic and Severe Mental Disorders, New York, Guilford Press, 3-17.

[38] Prasanth, A., Padma, V., Raju, N. N., Narasimha, R. M. (2010). A comparative study of care giver burden in psychiatric illness and chronic medical illness. AP J, Psychological Med, 11: 16-20.

[39] Atchison, M. Partridge, J. Twiss, J. (2017). Family Involvement and Support Networks. In Mary Chambers (Ed.) Psychiatric and Mental Health Nursing: The Craft of Caring. 3rd edition. London: Hodder Arnold. pp.559-569.

[40] McFarlane, W. (2016). Family psycho education for severe mental illness. In: Thomas, L. S. \& Jay, L. (Eds.) Handbook of family therapy. Routledge.

[41] Sawant, N. S., \& Jethwani, K. S. (2010). Understanding family functioning and social support in unremitting schizophrenia: A study in India. Indian Journal of Psychiatry, 52(2), 145-149. http://doi.org/10.4103/0019-5545.64593.

[42] Torres-González, F., Ibanez-Casas, I., Saldivia, S., et al. (2014). Unmet needs in the management of schizophrenia. Neuropsychiatr Dis Treat, 10, 97-110.

[43] Goldstein, M. J., Rosenfarb, I., Woo, S., Nuechterlein, K. (1994). Intrafamilial relationships and the course of schizophrenia. Acta Psych Scand, 90 Suppl 384, 60-6. 